Article

\title{
A Three-Player Game Model for Promoting the Diffusion of Green Technology in Manufacturing Enterprises from the Perspective of Supply and Demand
}

\author{
Manman Wang ${ }^{1}$, Shuai Lian ${ }^{2, *}$, Shi Yin ${ }^{3, *}$ (i) and Hengmin Dong ${ }^{4}$ \\ 1 College of Economics and Management, Zhengzhou University of Light Industry, Zhengzhou 450001, China; \\ 2020001@zzuli.edu.cn \\ 2 Zhengzhou Institute of Mechanical and Electrical Engineering, Zhengzhou 450001, China \\ 3 College of Economics and Management, Hebei Agricultural University, Baoding 071001, China \\ 4 China Academy of Aerospace Systems Science and Engineering, Beijing, 100048, China; \\ 13206550363@163.com \\ * Correspondence: 1s_hfut2016@163.com (S.L.); shyshi0314@163.com (S.Y.)
}

Received: 28 August 2020; Accepted: 12 September 2020; Published: 14 September 2020

check for updates

\begin{abstract}
Taking the rational use of environmental regulations to promote the diffusion of green technology innovation in China's manufacturing enterprises as the starting point, this study analyzed the benefits to the government, innovation-supplying enterprises, and potential demand-oriented enterprises. In addition, a tripartite evolutionary model was constructed to examine the impact of command-and-control environmental regulation and market-driven environmental regulation on the diffusion of green technology innovation in manufacturing enterprises. Finally, the study compared and analyzed the heterogeneous effects of different types of environmental regulation tools on the diffusion of green technology innovation in manufacturing enterprises using local stability analysis and numerical simulation. The results are as follows: (i) When the government does not implement environmental regulation tools or the regulation intensity is relatively small, the diffusion depth of green technology innovation in manufacturing enterprises is zero. (ii) When government regulation reaches a certain level, the system of manufacturing enterprises, innovation-supplying enterprises, and potential demand-oriented enterprises will choose to actively promote the diffusion of green technology innovation following a long evolution process. (iii) Increasing the punishment intensity and subsidy rate of green technology innovation can stimulate the diffusion of green technology innovation in manufacturing enterprises. (iv) The comprehensive use of the two kinds of environmental regulation tools has a heterogeneous influence on the strategic choice of green technology innovation diffusion subjects of manufacturing enterprises, and its incentive effect on potential demand-oriented enterprises is relatively poor.
\end{abstract}

Keywords: environmental regulation; manufacturing enterprise; diffusion of green technology innovation; tripartite evolutionary game

\section{Introduction}

The contradiction between economic development, energy consumption, and environmental pollution is increasingly stark. The manufacturing industry is the pillar of China's national economy and the main industrial cause of environmental pollution. Its traditional economic development mode, which focuses predominantly on scale expansion, is confronted with significant resource and environmental constraints. In addition, the lack of originality and high degree of imitation 
of manufacturing technology lead to high energy consumption and low utilization rates in the production process. Green technology innovation has increasingly become an important measure for manufacturing enterprises to balance resources and environmental challenges [1]. At present, Industry 4.0 is gradually driving the rapid development of global manufacturing towards an intelligent manufacturing mode. In contrast to the general requirements of manufacturing, Industry 4.0 focuses on intelligent products and production processes, in addition to green and sustainable development [2]. New manufacturing technologies, such as artificial intelligence (AI), Industrial Internet of Things (IIoT), 3D printing, and cloud-based platforms, have provided significant opportunities for industries that have reached the bottleneck of development and technical support for intelligent manufacturing in traditional industries [3]. Industry 4.0 coincides with China's development strategy, providing an important opportunity for the transformation and upgrade of Chinese manufacturing. China's 13th Five-Year Plan proposes a "green" development philosophy and encourages the implementation of innovation-driven development strategies. This indicates that green technology innovation, as a strategic basis, can benefit sustainable development and coordinate future energy use with environmental protection [4]. The China Government Work Report 2019 highlighted the need to address the difficult issues of energy conservation, emission reduction, and environmental governance, and accelerate the research and development of green technologies and products. China's traditional manufacturing industry is in urgent need of transformation and upgrading. Faced with the dual pressure of emission reduction from the international community and the ecological environment, manufacturing enterprises, as micro subjects of the manufacturing industry, are central to achieving the national goals of energy conservation and emission reduction, and industrial transformation and upgrading. However, the implementation of green technology innovation by Chinese manufacturing enterprises is in the primary stage and enthusiasm to do so is not high. Under the strong pressure of global environmental regulation, it is necessary to accelerate the green transformation of the manufacturing industry if the goal of transforming China from a large manufacturing country to a strong manufacturing country is to be realized.

In practice, most manufacturing enterprises in China are negligent in terms of environmental management, and tend to adopt passive and defensive environmental strategies. These enterprises are more likely to adopt terminal treatment technologies in the later stages of production than pollution prevention and control in the early stages of the production process. As a result, the production and operation costs of enterprises also remain at a high level and improving competitiveness remains a challenge. Furthermore, it is difficult to meet the growing demand of consumers for green products [5]. Due to worsening resource scarcity and greater attention being paid to environmental protection, manufacturing enterprises will seek to change from traditional production methods to intelligence and information approaches, from large-scale production to customized production, and from a product-oriented to a customer-oriented focus. Intelligent manufacturing, of which Industry 4.0 is the core, will be the inevitable trend for the future development of the manufacturing industry. In addition, this transition also represents an inevitable measure for China to actively adapt to the general trend of international development and promote the upgrading and transformation of traditional industries [6]. To cope with ongoing environmental problems and diversified green demands, the government will be more active in using administrative and economic means to improve the intensity of environmental regulation. Blaut proposed that the role of innovation diffusion is more important than innovation itself, and the impact of innovation on the economy is realized through innovation diffusion [7]. Mulder et al. found inefficiency in the diffusion of green technology innovation in numerous studies [8]. The diffusion of green technology innovation is slow due to its conflict with the existing institutional environment. According to the new institutional economics, the main institutional factor restricting the innovation of green technology is the free use of environmental resources, which is an externality $[9,10]$. Therefore, the main hurdle to the diffusion of green technology innovation lies in the internalization of external effects, including ensuring that polluters pay and the realization of the personal benefits of green technology innovation. In the case in which it is difficult 
for green technology innovation to spread among manufacturing enterprises, the government plays a guiding role through environmental regulation to stimulate manufacturing enterprises to undertake green technology innovation diffusion. Generally, environmental regulations in China comprise two main types, namely command-and-control and the market-based [11]. Against the background of the government's strict environmental regulation policies, manufacturing enterprises should actively promote the diffusion of green technology innovation and take the initiative to formulate environmental management strategies based on the green development model [12]. In addition, to ultimately achieve a coordinated and sustainable development of the economic society and ecological environment, manufacturing enterprises should strive to minimize their environmental pollution. Because of the critical implications for policy making on green innovation growth and the sustainable development of manufacturing enterprises, scholars have expressed significant concerns about the environmental regulations that enable elimination of environmental externalities and induce the diffusion of green technology innovation $[13,14]$. Hence, it is critical to take full account of the impact of different types of environmental regulations and to deepen understanding about the impact of environmental regulation on the diffusion of green technology innovation.

Scholars have undertaken significant research into innovation diffusion. One aspect relates to the influences on innovation diffusion. For example, Delre et al. proposed that information dissemination, the selection of marketing channels, and the formulation of pricing strategies has an important impact on the process and results of the diffusion of technology innovation [15]. D'Orazio et al. employed an agent-based model to study the effects of demand preferences, firms' innovation activities, and financial constraints on innovation projects. Results showed that green finance coupled with consumers' strong preference for environmental quality leads to a more pronounced diffusion of green innovation [16]. Gao and Zhang analyzed the path relationship between foreign investment, innovation capacity, and environmental efficiency using structural equation models. Results showed that foreign capital can promote the environmental efficiency of the funded region by improving the local innovation capacity through technology diffusion [17].

Another aspect is the influence of innovation resistance on innovation diffusion. For example, Zsifkovits et al. studied the influence of innovation resistance on innovation diffusion, and proposed that innovation resistance can hinder adoption and change a decision maker's evaluation [18]. The third aspect is the impact of government regulation on innovation diffusion. Coad et al. found that government policy information, including information disclosure, regulations, and financial incentives, such as subsidies or fines, played a significant role in guiding the innovation diffusion of clean vehicles [19]. Shi and Tong employed the logistic regression method to focus on the main factors affecting the spread of transnational green technology, and found that environmental regulatory standards in target markets had the greatest impact on technology diffusion [20].

To summarize, the research on the diffusion of technology innovation is relatively deep, but most research methods are empirical, and the research objects are usually examined in isolation. Green innovation is faced with a complex and changeable environment, with multi-agent participation. Empirical analysis is subject to issues of experimental data, sample selection, experimenters' or interviewees' experience limitations, and subjective judgments, which results in randomness and variability of empirical results [21]. In reality, enterprises are faced with incomplete information and imperfect rationality in the decision-making process. However, evolutionary game theory has the advantages of the bounded rationality hypothesis and incomplete information, which is applicable to the dynamic decision-making of enterprises in the process of competition. Some scholars have employed evolutionary game methods to study the diffusion of technology innovation. For example, $\mathrm{Xu}$ and Qi used a scale-free network as a diffusion carrier and established models of potential adoptive enterprises' decision making and low-carbon technological innovation diffusion under market mechanisms and government regulation based on the evolutionary game theory of networks [22]. Xu et al. constructed an evolutionary game model for the government and enterprises, and explored the impact of government regulation on enterprise service innovation behavior, evolution, and diffusion [23]. 
However, most previous research has focused on the game relationship between two parties. In addition, the relationship between the internal decision-making subjects of manufacturing enterprises has been ignored from the micro perspective. This paper aims to describe the evolution process of the mutual adaptation and adjustment of the decision-making behaviors of three parties, namely government, innovation-supplying enterprises, and potential demand-oriented enterprises. Based on this perspective, in this study a trilateral evolutionary game model of the government, innovation-supplying enterprises, and potential demand-oriented enterprises was constructed, and the evolutionary stable strategies of the three parties were analyzed. Finally, the theoretical results were verified by numerical simulation. This research aims to provide targeted and operational economic and environmental countermeasures for China's manufacturing industry to explore the green and sustainable development mode under the dual constraints of the environment and natural resources. In addition, it provides decision support and an effective reference for relevant national departments to formulate policies and make contributions to the further improvement of the theoretical relationship between environmental regulation and green technology innovation.

The remainder of this paper is organized as follows. Section 2 briefly provides a literature review. Section 3 presents the subject of diffusion of green technology innovation and the associated benefits. The tripartite evolutionary game model and evolutionary stability analysis are presented in Section 4 . Section 5 depicts the results of numerical simulation. Finally, Section 6 concludes with the major findings and some key policy implications.

\section{Literature Review}

\subsection{Green Technology Innovation}

It is necessary to review and scientifically define the concept of green technology innovation, which is also the foundation and starting point of this research. The existing literature presents similar concepts of green technology innovation, such as sustainable innovation, eco-innovation, and environmental technology innovation. However, a degree of difference exists between these four confusing concepts. Of these concepts, sustainable innovation can be traced back to the "World Natural Resources Conservation Outline" released by the United Nations Union for Nature and Natural Resources Protection in 1980, which described sustainable development as a close combination of conservation and development to protect the sustainable development and utilization of the earth's resources. Subsequently, the most representative definition has been provided by the European Union's research project "Sustainable Technology Innovation Policy for the 21st Century", which refers to technological innovation based on the perspective of sustainable development, including integrating sustainable development priorities into the innovation process or innovation output. The concept of eco-innovation is related to sustainable manufacturing. Rennings first defined eco-innovation as a fundamental or progressive innovation activity conducive to pollution reduction and ecological improvement [24]. Cai and $\mathrm{Li}$ believed that eco-innovation is a new concept of great significance for business and policy makers. It can reduce the environmental impact of technology innovation or non-technology innovation, whether the purpose is for economic or environmental purposes [25]. Shahin et al. defined eco-innovation as systematic innovation oriented to promote sustainable development [26]. In contrast to eco-innovation, Oltra and SaintJean defined environmental technology innovation as new or improved processes, practices, systems, and products that are beneficial to the environment and environmental sustainability [27]. Hurley et al. believed that environmental technology innovation refers to product innovation, process innovation, marketing innovation, and organizational innovation to achieve environmental protection goals [28]. Yin et al. believed that environmental technology innovation is an improved or new technology, process, or product developed to reduce environmental pollution [29].

It can be seen from the above description that sustainable innovation, eco-innovation, and environmental technology innovation can only be used as a means of sustainable development, 
and that these concepts do not aim at improving economic efficiency. The definition of green technology innovation takes into account both "innovation" and "environmental benefits". Green technology innovation was first mentioned in 1996 by Fussler and James who defined green innovation as new products and processes that can significantly reduce their environmental impact [30]. Driessen and Hillebrand defined green technology innovation from the perspective of practicality as innovation that can lead to significant environmental benefits, but not for the purpose of reducing environmental burden [31]. The Organization for Economic Co-operation and Development (OECD) proposed that green technology innovation refers to the creation of new products, processes, and marketing methods that are not developed or improved for the purpose of environmental improvement [32]. Xie et al. considered that green technology innovation consists of green innovation in the three aspects, namely process, product, and consciousness, aiming at achieving sustainable development goals [33].

\subsection{Diffusion of Green Technology Innovation}

Diffusion of technological innovation is regarded as a sub-process of technological innovation, and its concept originates from the innovation theory initiated by Joseph Schumpeter. He pointed out that technological innovation is a double-edged sword, which can not only help enterprises to achieve monopoly profits, but also lead to the problem of competitive imitation among enterprises. This phenomenon of large-scale "imitation" of technological innovation represents the diffusion of technological innovation. The diffusion of technological innovation has drawn wide attention in academic circles for a number of decades. However, the concept of the diffusion of technological innovation in enterprises has not been unified, and it is understood from different perspectives. Stoneman proposed that the diffusion of technological innovation is the process of large-scale commercial application followed by the first commercial application of technological innovation results [34]. Rogers suggested that the process of technological innovation diffusion is that innovation is spread to members of a social group through certain channels over a period of time [35]. Diffusion of green technology innovation is a new field of research on the diffusion of innovation, arising the recent development of green technology. From the perspective of evolution theory, green technology innovation is a new technology paradigm completely different from traditional technology, whose diffusion is restricted by multiple factors such as technological opportunity, selection environment, and learning effect. At present, the related research on diffusion of green technology innovation mainly focuses on the following three areas: (1) Green technology and its adoption applications, such as new energy storage technologies [36,37], carbon capture and storage [38] for the mitigation of renewable energy fluctuation [39,40], and new types of energy efficient telecommunications equipment [41,42]. (2) The influencing factors of the diffusion of green technology innovation including awareness [43,44], technical risk [45,46], transaction cost [47,48], and unfamiliarity with green technology $[49,50]$. (3) Related research on the role of government tools in the diffusion of green technology innovation. This research area includes two additional aspects: the study of carbon emission regulation [51,52], and investigation of government subsidies and incentive strategies from different perspectives $[53,54]$.

\subsection{Environmental Regulation and Diffusion of Green Technology Innovation}

Overall, the majority of recent studies aim at studying the impact of environmental regulation on the diffusion of green technology innovation. The research mostly focuses on how environmental regulation such as punishment or government subsidies affects the strategic selection of different agents. For example, Crespi et al. pointed out that in the process of ecological innovation and the evolution of relevant environmental policies, the boundary between environmental and technological policies is increasingly blurred [55]. $\mathrm{Xu}$ and $\mathrm{Xu}$ found that, when the supervision of government is enhanced, the probability of enterprises being fined for evading this supervision also increases, and enterprises tend to adopt strategies that can effectively avoid risks [56]. Cao et al. analyzed the impact of government regulation on the new energy automobile industry, and concluded that the greater the 
punishment by government for the emission of pollution by automobile manufacturers, the more favorable it will be for the enterprises to evolve towards the production of new energy vehicles [57]. Luigi and Andrea found that government subsidies for innovation input can increase the R\&D cost of enterprises, reduce the risk of innovation activities, and intensify the phenomenon of innovation competition among enterprises [58]. Cantono and Silverberg considered the heterogeneity of consumer preferences and empirically concluded that limited subsidy policies promoted the diffusion of green technologies [59]. Krass et al. constructed a Stackelberg model of the effect of carbon tax on enterprise innovation and carbon emission reduction technology, and found that under the appropriate carbon tax rate, enterprises are willing to reduce carbon emissions by adopting low-carbon technologies [60]. Gil-Molto et al. showed through simulation results that the impact of technological innovation on the carbon tax rate changed from positive to negative [61]. Cohen et al. found that government subsidies for green technology adoption offered directly to consumers impact the supplier's production and pricing decisions while considering the manufacturing industry's response [62].

Based on the above review, little research exists on the diffusion of green technology innovation in academic circles, and no research has considered the influence of the interaction between green technology innovation subjects in manufacturing enterprises on the diffusion of innovation. Under environmental regulations, how does green technology innovation diffuse within manufacturing enterprises? What should governments and manufacturers do to accelerate this diffusion? These problems have not been effectively addressed. Thus, this study attempted to advance the research in this field. Furthermore, different types of environmental regulation have heterogeneous impacts on the diffusion of green technology innovation among manufacturing enterprises. The decision-making behaviors relating to green technology innovation among manufacturing enterprises also influence each other. Therefore, to encourage manufacturing enterprises to implement green innovation and provide a decision basis for the government to achieve the goal of energy conservation and emission reduction, it is necessary to closely study the process and mechanism of the diffusion of green technology innovation in manufacturing enterprises under environmental regulation.

Hence, we make a contribution to the studies discussed above in several ways. First, we analyze the subject of the diffusion of green technology innovation and the associated benefits. Second, we construct an innovative tripartite evolutionary game model of the diffusion of green technology innovation in manufacturing enterprises. To this end, the impact of the evolution mechanism of different kinds of environmental regulation on the diffusion of green technology innovation among the three parties is analyzed through simulation.

\section{Theoretical Framework}

\subsection{The Subject of Diffusion of Green Technology Innovation}

Based on the above analysis, this paper proposes that green technology innovation is defined as the creative activities of manufacturing enterprises in new processes, technologies, systems, products, and environmental management to avoid or reduce environmental damage, with the purpose of obtaining long-term green and sustainable competitive advantages. Furthermore, the research object of this paper is the diffusion of green technology innovation in manufacturing enterprises. Based on the definition of technology innovation diffusion in academic circles, this paper holds that the diffusion of green technology innovation in manufacturing enterprises refers to the process in which innovation-supplying enterprises transfer the achievements of green technology innovation to the potential demand-oriented enterprises. Alternatively, the potential demand-oriented enterprises purchase the achievements of green technology innovation from the innovation-supplying enterprises. As a result, the process promotes sustainable economic development.

Innovation-supplying enterprises are companies that own the achievements of green technology innovation and are willing to spread them to other organizations. This kind of manufacturing enterprise 
has reformed the original manufacturing technique and technical process through independent research and the introduction of cooperative innovation. Furthermore, these manufacturing enterprises have realized green operation and production, and finally achieved the benefits of green technology innovation. In the initial stage, these enterprises gained a monopoly advantage, which gradually decreases or disappears with the increase of the number of manufacturing enterprises adopting green production. At this point, manufacturing enterprises take the initiative to transfer the achievements of green technology innovation to other potential demand-oriented enterprises. In view of the differences in technological level, interest demands, and development requirements, the manifestations of innovation-supplying enterprises in the diffusion of green technology innovation are heterogeneous. However, most are in the form of the transfer and spread to potential demand-oriented enterprises.

Potential demand enterprises belong to the demand subject in the diffusion system of green technology innovation. This type of manufacturing enterprise does not carry out green technology innovation, and continues to use original technical processes. Generally, these enterprises are characterized by relatively low energy efficiency, high pollution emissions, and backward green manufacturing techniques. If significant demand for green products exists, or manufacturing enterprises are forced by environmental requirements of energy conservation and emission reduction (for example, the government stipulates that manufacturing enterprises must meet technical standards and environmental standards), manufacturing enterprises with low green technology levels will directly purchase and adopt the mature achievements of external green technology innovation to obtain the effect of green technology innovation as soon as possible.

The diffusion of green technology innovation is actually the process of "output-input-output" of achievements of green technology innovation. The output and input processes of achievements of green technology innovation are realized by the innovation-supplying enterprises and the potential demand-oriented enterprises, which respectively represent the supplier and demander of the diffusion system of green technology innovation. This paper focuses on the innovation-supplying enterprises and potential demand-oriented enterprises in the diffusion system of green technology innovation.

\subsection{Analysis of the Subject Benefits}

From the perspective of innovation-supplying enterprises, when manufacturing enterprises have a monopoly advantage of green technology innovation, the diffusion of green technology innovation usually takes place passively, such as in government macro controls, or via an unknown means, such as in information leakage of achievements of innovation. In practical terms, when the government implements regulatory measures, the probability that innovation-supplying enterprises share green technology innovation with other enterprises increases. The monopoly advantage due to the implementation of green technology innovation is gradually reduced with the passing of time. Then, innovation-supplying enterprises will diffuse the achievements of green technology innovation to other potential demand-oriented enterprises. Diffusion modes are the one-off transfer of technology ownership, or the retention of technology ownership and transfer of the right to use the technology. Innovation-supplying enterprises can supply more than one demander when adopting the latter approach, thus a one-to-many diffusion pattern is formed.

From the perspective of potential demand-oriented enterprises, with the development of green and low-carbon economy, the market scale of green products grows rapidly. Public recognition and demand for green products increases. The government will implement the tools of reward and punishment to guide potential demand-oriented enterprises to purchase the achievements of green technology innovation and stimulate potential demand-oriented enterprises to adopt the achievements of green technology innovation. Specifically, in the context of the government's strict environmental regulation policies, potential demand-oriented enterprises develop the desire to adopt green technology innovation motivated by the need to reduce pollution emissions, improve energy efficiency, expand market share, and improve competitive advantage. Compared with high investment and high risk of 
independent research and development, it is simpler and more effective to buy directly and adopt mature external achievements of green technology innovation.

The above analysis shows that manufacturing enterprises, as the decision-making body, will consider the input and income of a specific green technology innovation when they choose to adopt it in the process of diffusion of green technology innovation. Innovation-supplying enterprises and potential demand-oriented enterprises will make choices based on the choices and information of other subjects, which reflects the game relationship between decision-making subjects. In the process of learning and imitation, both players seek better strategies through constant trial and error and selection until they reach equilibrium. Overall, under environmental regulations, achievements of green technology innovation are gradually adopted by potential demanders, and new adopters gradually become potential innovation suppliers due to the deepening of diffusion. The sources of diffusion continue to increase, while the potential demand-oriented enterprises gradually decrease to zero, which means that the diffusion process is completely finished.

Evolutionary game theory integrates game theory analysis and a dynamic evolution process. It is an important analytical tool for economic models to study the technology innovation of enterprises. Compared with traditional game theory, which focuses on static equilibria, evolutionary game theory pays more attention to dynamic equilibria. Its basic idea is that the game party carries out game activities repeatedly in a game group with a certain scale. Assuming that the players are in the state of bounded rationality and bound by a certain rule and game structure, it is necessary to choose the optimal strategy through constant imitation. In addition, for the sake of the influence of exogenous factors such as the environment, all players have repeated games in the long process of imitation and improvement, and finally reach equilibrium [63]. In combination with the actual research, the evolution process of diffusion of green technology innovation in manufacturing enterprises under environmental regulation requires the participation of three stakeholders, namely the government, innovation-supplying enterprises, and potential demand-oriented enterprises. First, the interaction between the government, innovation-supplying enterprises, and potential demand-oriented enterprises has an important impact on the strategic selection of all parties, which reflects the game relationship between the subjects of decision-making [64]. Second, the complexity of and difference between many factors in the decision-making process, such as structure, combination, and configuration, determines the bounded rationality of the choice and judgment of the agent. Finally, when the technology and market environment change, the decision-making behavior of manufacturing enterprises also changes dynamically. Evolutionary game theory emphasizes that decision-making behavior is the result of a mutual adjustment of subject behavior, which is consistent with the characteristics of the diffusion of green technology innovation. Diffusion is the dynamic evolution of the mutual adjustment of all parties' behaviors under certain rules. Therefore, to reflect the dynamic game process of environmental regulation on the diffusion of green technology innovation in manufacturing enterprises, this study employed evolutionary game theory and numerical simulation to analyze the dynamic game process. The study determines the evolution and stability strategy of the three parties in different situations to reach the ideal state by constructing a tripartite evolution game model of government, innovation-supplying enterprises, and potential demand-oriented enterprises. Furthermore, it provides a decision-making reference for encouraging manufacturing enterprises to carry out green innovation and promote the realization of government's goal of energy conservation and emission reduction.

The game relationships among the government, innovation-supplying enterprises, and potential demand-oriented enterprises are shown in Figure 1. 


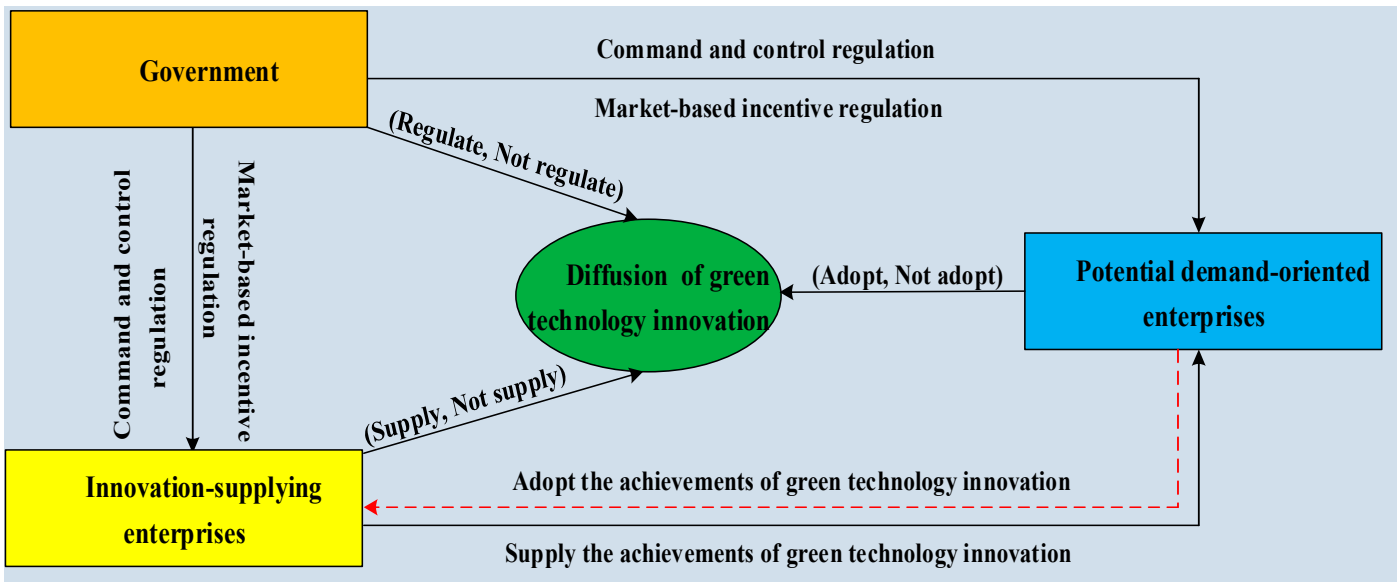

Figure 1. Illustration of the game relationships among the government, innovation-supplying enterprises, and potential demand-oriented enterprises.

\section{An Evolutionary Game Analysis of the Diffusion of Green Technology Innovation}

\subsection{Tripartite Evolutionary Game Model}

\subsubsection{Game Model Construction}

To establish the evolutionary game model of the diffusion of green technology innovation, the related assumptions and parameters are given as follows:

\section{(1) Game player}

The study assumes that the game involves three participants, namely the government, innovation-supplying enterprises, and potential demand-oriented enterprises, in a "natural" state without other constraints, which are regarded as a system. Moreover, each of the three parties has limited rationality and corresponding learning and imitation ability. In addition, they can form and adjust their own strategies through learning and imitating similar players.

\section{(2) Behavioral strategies of all players}

In the game of diffusion of green technology innovation, to encourage manufacturing enterprises to carry out the diffusion of green technology innovation and reduce their economic losses from diffusion, the government can choose to adopt environmental regulation tools, thus setting the selection strategy (regulate, not regulate). For the sake of their own interests, innovation-supplying enterprises can choose to supply the achievements of green technology innovation or not, and the selection strategy set is (supply, not supply). Potential demand-oriented enterprises can choose to adopt the achievements of green technology innovation according to their own needs or not, and the selection strategy set is (adopt, not adopt).

(3) Model hypothesis

Hypothesis 1 (H1). Under the condition of bounded rationality, the government, innovation-supplying enterprises, and potential demand-oriented enterprises freely choose strategies according to their will. The probability that the government chooses the strategy of "regulate" and "not regulate" is respectively $x(0 \leq x \leq 1)$ and $1-x$.The probability of innovation-supplying enterprises choosing the strategy of "supply" and "not supply" is respectively $y(0 \leq y \leq 1)$ and $1-y$. The probability of demand-oriented enterprises choosing the strategy of "adopt" and "not adopt" is respectively $z(0 \leq z \leq 1)$ and $1-z x, y$, and $z$ are functions of time. 
Hypothesis $2 \mathbf{~ ( H 2 ) . ~ T h e ~ i n n o v a t i o n ~ i n v e s t m e n t ~ o f ~ e n t e r p r i s e s ~ i n ~ r e s e a r c h ~ a n d ~ d e v e l o p m e n t ~ o f ~ g r e e n ~ t e c h n o l o g y ~}$ will have positive externalities. $C_{M}$ and $C_{N}$ represent innovation inputs of green technology adoption by innovation-supplying enterprises and potential demand-oriented enterprises, respectively. $I_{M}$ and $I_{N}$ represent the innovation benefits to innovation-supplying enterprises and potential demand-oriented enterprises by adopting green technologies, respectively. $R_{N}$ represents the normal earnings of potential demand-oriented enterprises when they do not adopt green technologies. P represents the one-time purchase cost of green technology innovation achievements by potential demand-oriented enterprises from innovation-supplying enterprises. The reduction of monopoly advantage after the successful sale of green technology innovations by innovation-supplying enterprises brings additional losses $W$.

Hypothesis 3 (H3). The government adopts two kinds of regulation tools, namely command and control regulation and market-based incentive regulation. Command and control regulation mainly comprises the tools of collecting pollution fines from enterprises. Pollution fines refer to the fines imposed by the government on an enterprise that fails to carry out green technology innovation and thus causes excessive emission of pollution. The government takes punitive measures against those who do not choose green technology. Supposing that the punishment intensity is $\lambda$, the innovation-supplying enterprises and potential demand-oriented enterprises will suffer losses of $\lambda O_{M}$ and $\lambda O_{N}$, respectively, if they are punished. Market-based incentive regulation mainly comprises the tools of subsidizing enterprises according to their investment in green technology innovation. Input subsidies refer to subsidies for enterprises to adopt investment in green technology innovation in a certain proportion. Suppose the subsidy rate of green innovation input from the government to manufacturing enterprises is $\mu(0 \leq \mu \leq 1)$. In addition, the government bears the regulatory costs $S$ of environmental pollution caused by traditional production and operation of enterprises.

The strategic selection of the players in the process of the diffusion of green technology innovation finally constitutes the strategic combination for the tripartite evolutionary game among the government, innovation-supplying enterprises, and potential demand-oriented enterprises. This is shown in Table 1.

Table 1. The strategic combination for the tripartite evolutionary game among the government, innovation-supplying enterprises and potential demand-oriented enterprises.

\begin{tabular}{cccc}
\hline $\begin{array}{c}\text { Strategic } \\
\text { Combination }\end{array}$ & Government & $\begin{array}{c}\text { Innovation-Supplying } \\
\text { Enterprises }\end{array}$ & $\begin{array}{c}\text { Potential Demand-Oriented } \\
\text { Enterprises }\end{array}$ \\
\hline 1 & Regulate & Supply & Adopt \\
2 & Regulate & Supply & Not Adopt \\
3 & Regulate & Not Supply & Adopt \\
4 & Regulate & Not Supply & Not Adopt \\
5 & Not Regulate & Supply & Adopt \\
6 & Not Regulate & Supply & Not Adopt \\
7 & Not Regulate & Not Supply & Adopt \\
8 & Not Regulate & Not Supply & Not Adopt \\
\hline
\end{tabular}

Based on the above parameters and assumptions, the pay-off matrix among the government, innovation-supplying enterprises, and potential demand-oriented enterprises is shown in Table 2. 
Table 2. The revenue of the game matrix among the government, innovation-supplying enterprises, and potential demand-oriented enterprises.

\begin{tabular}{|c|c|c|c|c|c|}
\hline \multicolumn{3}{|c|}{ Game Player } & \multicolumn{3}{|c|}{ Potential Demand-Oriented Enterprises } \\
\hline & & & & Adopt (z) & Not Adopt $(1-z)$ \\
\hline Government & $\begin{array}{c}\text { Not Regulate }(1- \\
\mathrm{x})\end{array}$ & $\begin{array}{l}\text { Innovation-supplying } \\
\text { Enterprises }\end{array}$ & $\begin{array}{c}\begin{array}{c}\text { Supply } \\
\text { (y) }\end{array} \\
\text { Not Supply } \\
(1-\mathrm{y}) \\
\text { Supply } \\
\quad \text { (y) } \\
\text { Not Supply } \\
\text { (1-y) }\end{array}$ & $\begin{array}{c}-\mu\left(C_{M}+C_{N}\right) \\
I_{M}+P-(1-\mu) C_{M}-W \\
I_{N}-P-(1-\mu) C_{N} \\
\lambda O_{M}-\mu C_{M}-S \\
I_{M}-\lambda O_{M}-(1-\mu) C_{M} \\
R_{N} \\
0 \\
{\left[\begin{array}{c}I_{M}+P-W \\
I_{N}-P \\
-S \\
I_{M} \\
R_{N}\end{array}\right]}\end{array}$ & $\begin{array}{c}{\left[\begin{array}{c}-\mu C_{M}+\lambda O_{N}-S \\
I_{M}-(1-\mu) C_{M} \\
R_{N}-\lambda O_{N}\end{array}\right]} \\
\lambda\left(O_{M}+O_{N}\right)-\mu C_{M}-S \\
I_{M}-\lambda O_{M}-(1-\mu) C_{M} \\
R_{N}-\lambda O_{N} \\
{\left[\begin{array}{c}-S \\
I_{M} \\
R_{N}\end{array}\right]} \\
{\left[\begin{array}{c}-S \\
I_{M} \\
R_{N}\end{array}\right]}\end{array}$ \\
\hline
\end{tabular}

\subsubsection{Game Model Solution and Analysis}

As shown in Table 2, the expected revenue of the government based on the strategies of "regulate" or "not regulate" is $U_{G 1}$ and $U_{G 2}$, respectively. The average expected revenue is $\overline{U_{G}}$.

$$
\begin{gathered}
U_{G 1}=y z(-\mu)\left(C_{M}+C_{N}\right)+y(1-z)\left(-\mu C_{M}+\lambda O_{N}-S\right)+z(1-y) \\
\left(\lambda O_{M}-\mu C_{M}-S\right)+(1-y)(1-z)\left[\lambda\left(O_{M}+O_{N}\right)-\mu C_{M}-S\right] \\
U_{G 2}=y z * 0+y(1-z)(-S)+z(1-y)(-S)+(1-y)(1-z)(-S) \\
\overline{U_{G}}=x U_{G 1}+(1-x) U_{G 2}
\end{gathered}
$$

The expected revenue of the innovation-supplying enterprises choosing the strategies of "supply" or "not supply" is $U_{M 1}$ and $U_{M 2}$, respectively. The average expected revenue is $\overline{U_{M}}$.

$$
\begin{gathered}
U_{M 1}=x z\left[I_{M}+P-(1-\mu) C_{M}-W\right]+z(1-x)\left(I_{M}+P-W\right)+x(1-z) \\
{\left[I_{M}-(1-\mu) C_{M}\right]+(1-x)(1-z) I_{M}} \\
U_{M 2}=x z\left[I_{M}-\lambda O_{M}-(1-\mu) C_{M}\right]+z(1-x) I_{M}+x(1-z) \\
{\left[I_{M}-\lambda O_{M}-(1-\mu) C_{M}\right]+(1-x)(1-z) I_{M}} \\
\overline{U_{M}}=y U_{M 1}+(1-y) U_{M 2}
\end{gathered}
$$

The expected revenue of the potential demand-oriented enterprises choosing the strategies of "adopt" or "not adopt" is $U_{N 1}$ and $U_{N 2}$, respectively. The average expected revenue is $\overline{U_{N}}$.

$$
\begin{gathered}
U_{N 1}=x y\left[I_{N}-P-(1-\mu) C_{N}\right]+y(1-x)\left(I_{N}-P\right)+ \\
x(1-y) R_{N}+(1-x)(1-y) R_{N} \\
U_{N 2}=x y\left(R_{N}-\lambda O_{N}\right)+y(1-x) R_{N}+x(1-y) \\
\left(R_{N}-\lambda O_{N}\right)+(1-x)(1-y) R_{N} \\
\overline{U_{N}}=z U_{N 1}+(1-z) U_{N 2}
\end{gathered}
$$

According to the evolutionary game theory, based on the above analysis, the replication dynamic equation of the government can be obtained from Equations (1)-(3):

$$
F(x)=d x / d t=x\left(U_{G 1}-\overline{U_{G}}\right)=x(1-x)\left[\lambda\left(O_{M}+O_{N}\right)-\lambda y O_{M}-z \lambda O_{N}-y z \mu C_{N}\right]
$$


The replication dynamic equation of the innovation-supplying enterprises can be obtained from Equations (4)-(6):

$$
F(y)=d y / d t=y\left(U_{M 1}-\overline{U_{M}}\right)=y(1-y)\left[x \lambda O_{M}+z P-z W\right]
$$

The replication dynamic equation of the potential demand-oriented enterprises can be obtained from Equations (7)-(9):

$$
F(z)=d z / d t=z\left(U_{N 1}-\overline{U_{N}}\right)=z(1-z)\left[x \lambda O_{N}+y\left(I_{N}-R_{N}-P\right)-x y(1-\mu) C_{N}\right]
$$

In the process of the diffusion of green technology innovation, the players of the tripartite game constantly play the game of strategy evolution, and evolve to the stable strategy. The equations of the replication dynamic system of the tripartite game of government, innovation-supplying enterprises, and potential demand-oriented enterprises are as follows:

$$
\left\{\begin{array}{c}
F(x)=x(1-x)\left[\lambda\left(O_{M}+O_{N}\right)-\lambda y O_{M}-z \lambda O_{N}-y z \mu C_{N}\right] \\
F(y)=y(1-y)\left[x \lambda O_{M}+z P-z W\right] \\
F(z)=z(1-z)\left[x \lambda O_{N}+y\left(I_{N}-R_{N}-P\right)-x y(1-\mu) C_{N}\right]
\end{array}\right.
$$

To determine the equilibrium point of the diffusion of green technology innovation between innovation-supplying enterprises and potential demand-oriented enterprises under government environmental regulation, we set $F(x)=0, F(y)=0, F(z)=0$, and we can draw two conclusions from the set $R=\{(x, y, z) \mid 0 \leq x \leq 1,0 \leq y \leq 1,0 \leq z \leq 1\}$. (1) There must be eight equilibrium points of pure strategy adopted by three parties, $E_{1}=(0,0,0), E_{2}=(0,0,1), E_{3}=(0,1,0), E_{4}=(1,0,0)$, $E_{5}=(1,1,0), E_{6}=(1,0,1), E_{7}=(0,1,1)$, and $E_{8}=(1,1,1)$. (2) There may be a mixed equilibrium point $E_{9}=\left(x^{*}, y^{*}, z^{*}\right)$ where $x^{*}, y^{*}, z^{*} \in(0,1)$ and Equation (14) is satisfied:

$$
\left\{\begin{array}{c}
\lambda\left(O_{M}+O_{N}\right)-\lambda y O_{M}-z \lambda O_{N}-y z \mu C_{N}=0 \\
x \lambda O_{M}+z P-z W=0 \\
x \lambda O_{N}+y\left(I_{N}-R_{N}-P\right)-x y(1-\mu) C_{N}=0
\end{array}\right.
$$

We set $\lambda O_{M}=a, \lambda O_{N}=b, I_{N}-R_{N}-P=c, \mu C_{N}=d, P-W=e$. The following equation can then be obtained by solving Equation (14):

$$
\left\{\begin{array}{c}
x^{*}=\frac{a b e^{2}-a g e^{2}+a b c e-b g e^{2}+b e^{2}}{2 b e(1-d)} \\
y^{*}=\frac{a b^{2} e^{2}-a b g e^{2}+a b^{2} c e-b^{2} g e^{2}+b^{2} e^{2}}{\left(a b e^{2}-a g e^{2}+a b c e-b e^{2}+b e^{2}-2 b c e\right)(1-d)} \\
z^{*}=\frac{a g e-a b e-a b c+b g e-b e}{2 b e(1-d)}
\end{array}\right.
$$

Further, derivation of the replication equation of the government, innovation-supplying enterprises, and potential demand-oriented enterprises can be obtained as follows:

$$
\left\{\begin{array}{c}
F^{\prime}(x)=(1-2 x)\left[\lambda\left(O_{M}+O_{N}\right)-\lambda y O_{M}-z \lambda O_{N}-y z \mu C_{N}\right] \\
F^{\prime}(y)=(1-2 y)\left[x \lambda O_{M}+z P-z W\right] \\
F^{\prime}(z)=(1-2 z)\left[x \lambda O_{N}+y\left(I_{N}-R_{N}-P\right)-x y(1-\mu) C_{N}\right]
\end{array}\right.
$$

According to the evolutionary game theory, the case in which $F^{\prime}(x), F^{\prime}(y)$, and $F^{\prime}(z)$ are all less than 0 represents the "evolutionary stability strategy" of the tripartite game among the government, innovation-supplying enterprises, and potential demand-oriented enterprises. This is referred to as the "ESS point". 


\subsection{Evolutionary Stability Analysis}

According to the stability theorem of the replication dynamic equation, it can be known that when $F(x)=0, F^{\prime}(x)<0, F(y)=0, F^{\prime}(y)<0, F(z)=0$, and $F^{\prime}(z)<0, x^{*}, y^{*}$, and $z^{*}$, respectively represent the stable strategies of the evolution of government, innovation-supplying enterprises, and potential demand-oriented enterprises.

\subsubsection{The Gradual Stability Analysis of Government Regulatory Department}

(1) When $\lambda\left(O_{M}+O_{N}\right)-\lambda y O_{M}-z \lambda O_{N}-y z \mu C_{N}=0, F(x)=0$ and $F^{\prime}(x)=0$. In this case, the stability strategy is unchanged regardless of whether the government regulatory department chooses the strategy of "regulate" or "not regulate". That is, the proportion of strategy does not change with time, which is the boundary of the stable state (as shown in Figure 2a).

(2) When $\lambda\left(O_{M}+O_{N}\right)-\lambda y O_{M}-z \lambda O_{N}-y z \mu C_{N}>0,\left.F^{\prime}(x)\right|_{x=0}>0$ and $\left.F^{\prime}(x)\right|_{x=1}<0$. In this case, the evolutionary stable state of the system is $x=1$, and the government chooses the "regulate" strategy. In contrast, the evolutionary unstable state of the system is $x=0$, and the government chooses the "not regulate" strategy. Therefore, government regulatory departments evolve towards the direction of choosing the "regulate" strategy (as shown in Figure 2b).

(3) When $\lambda\left(O_{M}+O_{N}\right)-\lambda y O_{M}-z \lambda O_{N}-y z \mu C_{N}<0,\left.F^{\prime}(x)\right|_{x=1}>0$ and $\left.F^{\prime}(x)\right|_{x=0}<0$. In this case, the evolutionary stable state of the system is $x=0$, and the government chooses the "not regulate" strategy. In contrast, the evolutionary unstable state of the system is $x=1$, and the government chooses the "regulate" strategy. Therefore, government regulatory departments evolve towards the direction of choosing the "not regulate" strategy (as shown in Figure 2c).

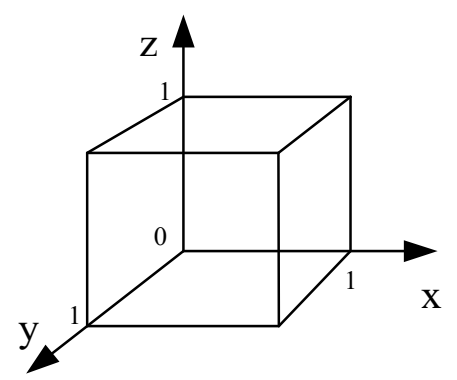

(a)

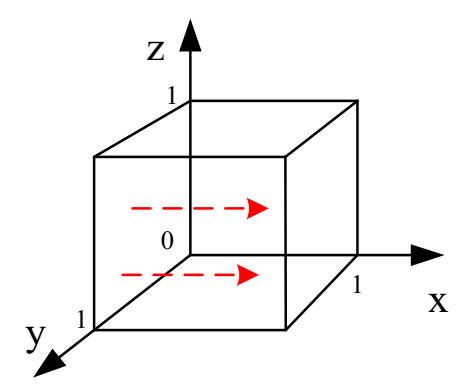

(b)

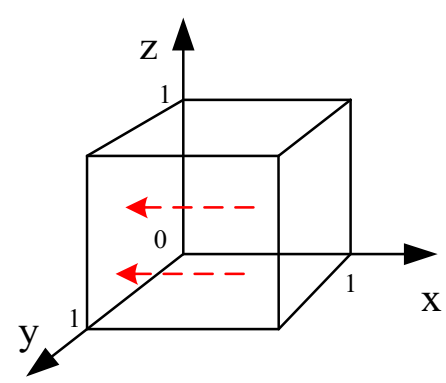

(c)

Figure 2. Dynamic evolution trend chart of government.

\subsubsection{The Gradual Stability Analysis of Innovation-Supplying Enterprises}

(1) When $x \lambda O_{M}+z P-z W=0, F(y)=0$ and $F^{\prime}(y)=0$. In this case, the stability strategy is unchanged regardless of whether the innovation-supplying enterprises choose the strategy of "supply" or "not supply". That is, the proportion of strategy does not change with time, which is the boundary of the stable state (as shown in Figure 3a).

(2) When $x \lambda O_{M}+z P-z W>0,\left.F^{\prime}(y)\right|_{y=0}>0$ and $\left.F^{\prime}(y)\right|_{y=1}<0$. In this case, the evolutionary stable state of the system is $y=1$, and the innovation-supplying enterprises choose the "supply" strategy. In contrast, the evolutionary unstable state of the system is $y=0$, and the innovation-supplying enterprises choose the "not supply" strategy. Therefore, the innovation-supplying enterprises evolve towards the direction of choosing the "supply" strategy (as shown in Figure $3 \mathrm{~b}$ ).

(3) When $x \lambda O_{M}+z P-z W<0,\left.F^{\prime}(y)\right|_{y=1}>0$ and $\left.F^{\prime}(y)\right|_{y=0}<0$. In this case, the evolutionary stable state of the system is $y=0$, and the innovation-supplying enterprises choose the "not supply" strategy. In contrast, the evolutionary unstable state of the system is $y=1$, and the innovation-supplying enterprises choose the "supply" strategy. Therefore, 
the innovation-supplying enterprises evolve towards the direction of choosing the "not supply" strategy (as shown in Figure 3c).

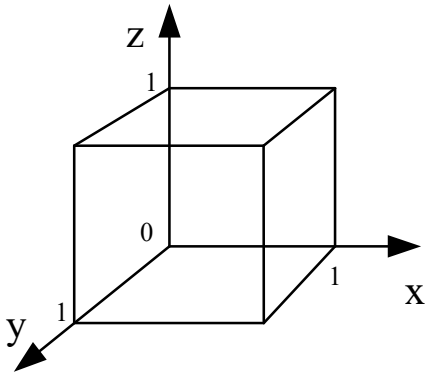

(a)

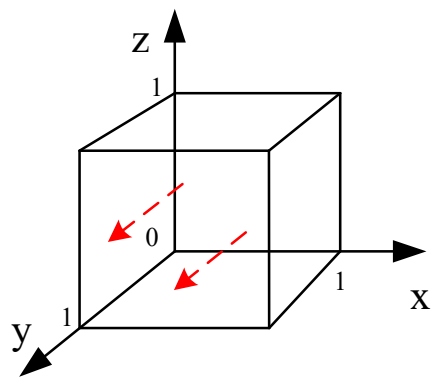

(b)

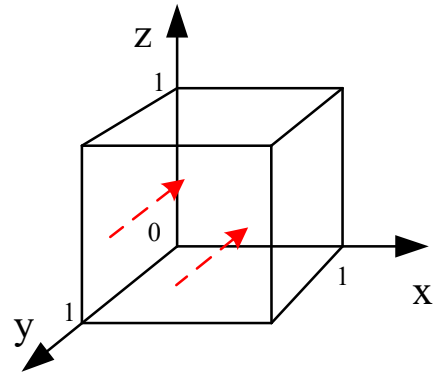

(c)

Figure 3. Dynamic evolution trend chart of innovation-supplying enterprises.

4.2.3. The gradual stability analysis of potential demand-oriented enterprises

(1) When $x \lambda O_{N}+y\left(I_{N}-R_{N}-P\right)-x y(1-\mu) C_{N}=0, F(z)=0$ and $F^{\prime}(z)=0$. In this case, the stability strategy is unchanged regardless of whether the potential demand-oriented enterprises choose the strategy of "adopt" or "not adopt". That is, the proportion of strategy does not change with time, which is the boundary of the stable state (as shown in Figure 4a).

(2) When $x \lambda O_{N}+y\left(I_{N}-R_{N}-P\right)-x y(1-\mu) C_{N}>0,\left.F^{\prime}(z)\right|_{z=0}>0$ and $\left.F^{\prime}(z)\right|_{z=1}<0$. In this case, the evolutionary stable state of the system is $z=1$, and the potential demand-oriented enterprises choose the "adopt" strategy. In contrast, the evolutionary unstable state of the system is $z=0$, and the potential demand-oriented enterprises choose the "not adopt" strategy. Therefore, the potential demand-oriented enterprises evolve towards the direction of choosing the "adopt" strategy (as shown in Figure 4b).

(3) When $x \lambda O_{N}+y\left(I_{N}-R_{N}-P\right)-x y(1-\mu) C_{N}<0,\left.F^{\prime}(z)\right|_{z=1}>0$ and $\left.F^{\prime}(z)\right|_{z=0}<0$. In this case, the evolutionary stable state of the system is $z=0$, and the potential demand-oriented enterprises choose the "not adopt" strategy. In contrast, the evolutionary unstable state of the system is $z=1$, and the potential demand-oriented enterprises choose the "adopt" strategy. Therefore, the potential demand-oriented enterprises evolve towards the direction of choosing the "not adopt" strategy (as shown in Figure 4c).

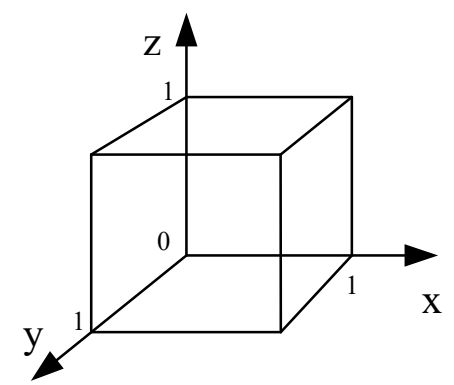

(a)

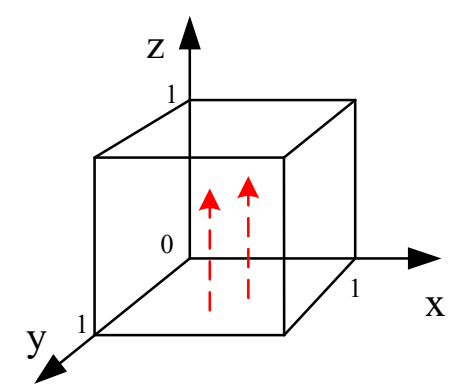

(b)

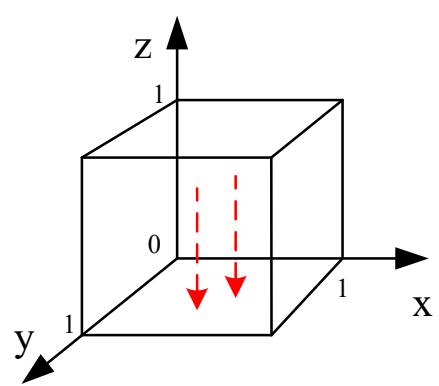

(c)

Figure 4. Dynamic evolution trend chart of potential demand-oriented enterprises.

\section{Numerical Simulation and Discussion}

To further study the evolution mechanism of the system according to the constraints and the replication of the dynamic equation, this study employed MATLAB software to simulate the evolution 
process of the system, government, innovation-supplying enterprises, and potential demand-oriented enterprises. Based on the actual situation and the basic assumptions of the model, the simulation parameters were set as $C_{M}=6, C_{N}=3, I_{M}=15, R_{N}=7, I_{N}=10, P=2, W=1, O_{M}=5, O_{N}=5$, and $S=7.5$. In this section, we discuss the main results, and provide explanations and some additional clarifications about these results.

\subsection{The Influence of Command and Control Regulation on the Strategy Selection of the Three Parties}

To comprehensively investigate the influence of command and control regulation on the evolution behavior of the tripartite game, the punishment intensity of the government for manufacturing enterprises not actively diffusing green technology innovation was evaluated as $0.1,0.3,0.5,0.7$, and 0.9 . The evolution path of the diffusion system of green technology innovation, the innovation-supplying enterprises, and the potential demand-oriented enterprises under different punishment intensities is shown in Figures 5-7.

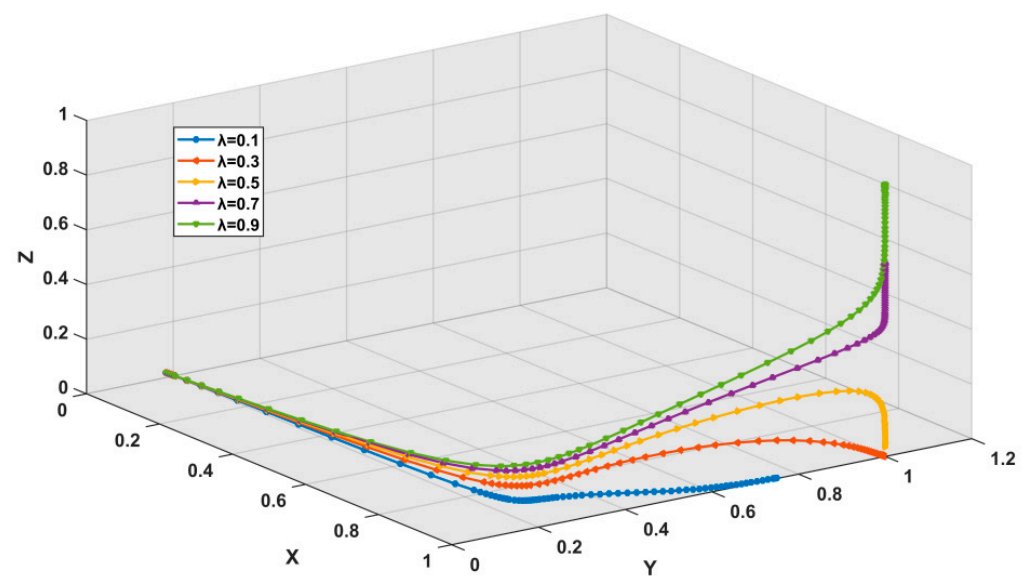

Figure 5. The influence of the change of $\lambda$ on the system's evolution trajectory.

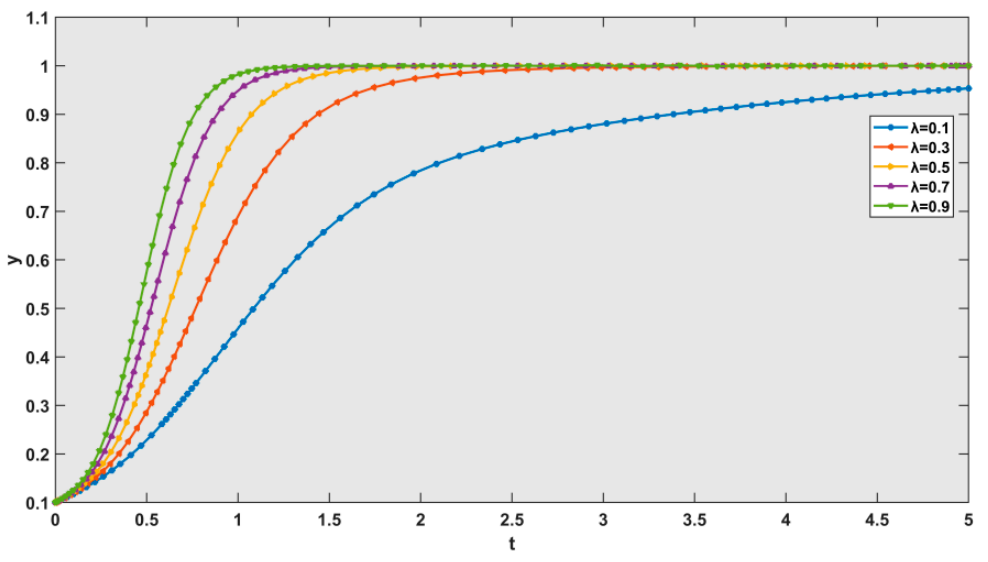

Figure 6. The influence of the change of $\lambda$ on the innovation-supplying enterprises' evolution trajectory. 


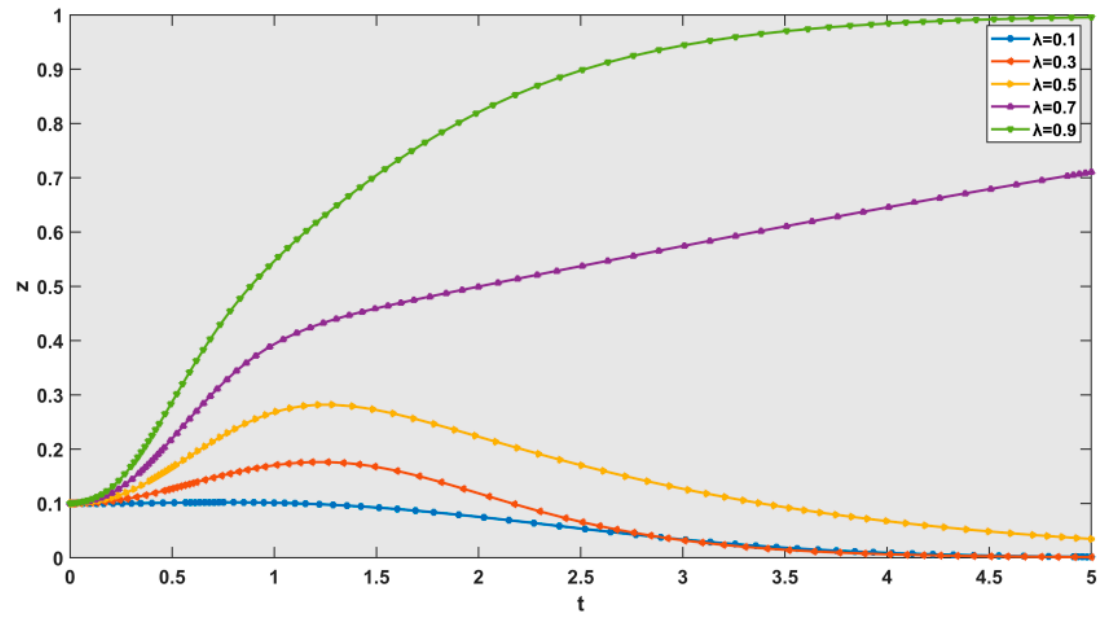

Figure 7. The influence of the change of $\lambda$ on the potential demand-oriented enterprises' evolution trajectory.

(1) The influence of command and control regulation on the system

It can be seen from Figure 5 that when the values of $\lambda$ are $0.1,0.3$, and 0.5 , the diffusion system of green technology innovation will eventually evolve to $(1,1,0)$. The system at this time represents a stable state in which the government chooses the "regulate" strategy, the innovation-supplying enterprises choose the "supply" strategy, and the potential demand-oriented enterprises choose the "not adopt" strategy. This means that the depth of diffusion of green technology innovation is zero. However, when the government's punishment intensity increased to 0.7 and 0.9 , the system finally converged to $(1,1,1)$ after a long game period. That is, the government eventually choose the "regulate" strategy, the innovation-supplying enterprises choose the "supply" strategy, and the potential demand-oriented enterprises choose the "adopt" strategy. The system reaches the ideal state of complete diffusion.

(2) The influence of command and control regulation on the innovation-supplying enterprises

According to the observation of Figure 6, when $\lambda=0.1$, that is, when the punishment intensity is relatively small, the innovation-supplying enterprises will ultimately choose not to supply the achievements of green technology innovation. However, when $\lambda>0.1$, all of the innovation-supplying enterprises choose the "supply" strategy after a long game period, at which point a stable situation is reached in which all enterprises choose to supply achievements of green technology innovation. To be specific, with the deepening of punishment intensity, the evolution speed of innovation-supplying enterprises to supply achievements of green technology innovation is improved to a certain extent, which indicates that the proportion of innovation-supplying enterprises that choose the "not supply" strategy steadily decreases.

At the present stage, China's green technology remains immature, and the large-scale popularization of the corresponding achievements of green technology innovation is still in the stage of improvement [65]. When innovation-supplying enterprises supply the achievements of green technology innovation to other enterprises, their monopoly advantages will be reduced. In this case, there will be no constraint on the innovation-supplying enterprises if the government's punishment policy is not strict enough, and the levying of fines cannot stimulate the innovation-supplying enterprises to diffuse the achievements of green innovation. If the government's punishment intensity is enough to offset the economic benefits brought about by the monopoly advantage of green technology, the innovation-supplying enterprises will choose to supply the achievements of green technology innovation to avoid losses. 
(3) The influence of command and control regulation on the potential demand-oriented enterprises

According to the observation of Figure 7, the potential demand-oriented enterprises will ultimately choose not to adopt the achievements of green technology innovation when $\lambda=0.1$, 0.3 , and 0.5. It is worth noting that when $\lambda$ changes from 0 to 0.5 , the evolution speed of potential demand-oriented enterprises to non-adoption behavior steadily slows, which indicates that the probability of non-adoption strategy steadily decreases. Some potential demand-oriented enterprises will eventually adopt the achievements of green technology innovation results when $\lambda=0.7$. The group of potential demand-oriented enterprises will evolve to a stable state in which they all adopt the achievements of green technology innovation when $\lambda=0.9$. In general, the levying of fines has an incentive effect on the speed at which potential demand-oriented enterprises adopt the achievements of green technology innovation. Furthermore, the greater the penalty intensity, the more obvious the incentive effect will be.

Existing traditional technologies have high market share and large profit margins. Traditional means of production and operation may require the payment of certain pollution fines. However, if the fines imposed by the government are at a low level, the potential demand-oriented enterprises will suffer fewer losses when they choose the "not adopt" strategy. Therefore, the potential demand-oriented enterprises will eventually tend to choose not to adopt the achievements of green technology innovation. When the punishment is very severe, the traditional technology adopted by potential demand-oriented enterprises cannot effectively reduce the pollution emission and the level of fines is beyond their capacity. To reduce the fines and improve profits, the proportion of potential demand-oriented enterprises choosing the "adopt" strategy will increase after many games. With the enhancement of punishment intensity, the adoption behavior of potential demand-oriented enterprises will evolve at a faster rate until all enterprises choose to adopt the achievements of green technology innovation. Therefore, the government should punish the potential demand-oriented enterprises that produce various pollutants if they choose the "not adopt" strategy to effectively promote the diffusion of green technology innovation within manufacturing enterprises [66].

\subsection{The Influence of Market-Based Incentive Regulation on the Strategy Selection of the Three Parties}

Similarly, the influence of market-based incentive regulation on the decision-making process and strategy selection of the three parties was analyzed by comparing the value of the variable parameters. The subsidy rate of green technology innovation input from the government to manufacturing enterprises was set as $0.1,0.3,0.5,0.7$, and 0.9 . The evolution path of the diffusion system of green technology innovation, the innovation-supplying enterprises, and the potential demand-oriented enterprises under different subsidy rates is shown in Figures 8-10.

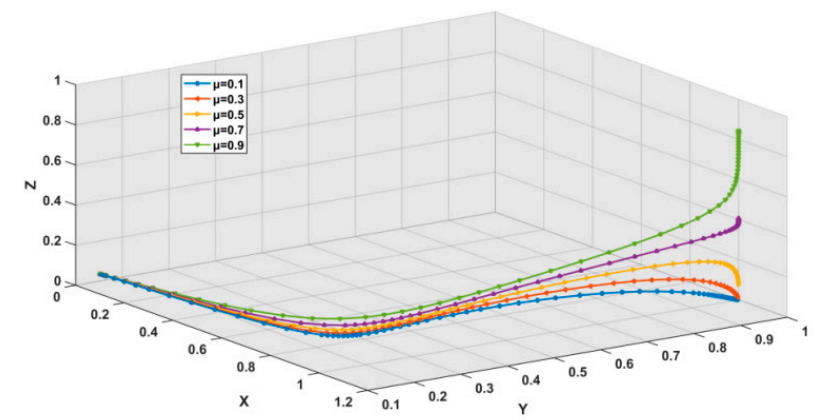

Figure 8. The influence of the change of $\mu$ on the system's evolution trajectory. 


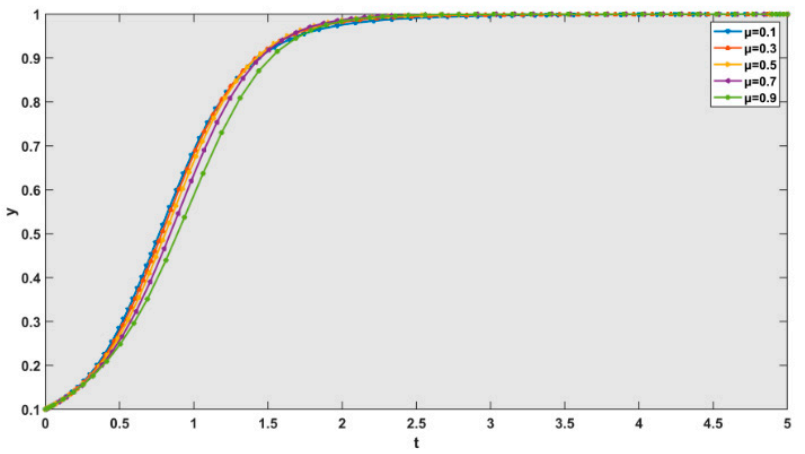

Figure 9. The influence of the change of $\mu$ on the innovation-supplying enterprises' evolution trajectory.

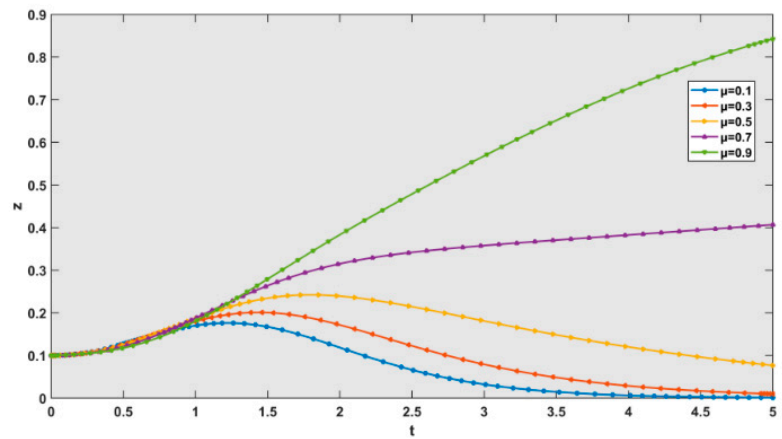

Figure 10. The influence of the change of $\mu$ on the potential demand-oriented enterprises' evolution trajectory.

(1) The influence of market-based incentive regulation on the system

It can be seen from Figure 8 that when $\mu$ values are 0.1 and 0.3 , the diffusion system of green technology innovation will eventually evolve to $(1,1,0)$. The system at this time represents a stable state in which the government chooses the "regulate" strategy, the innovation-supplying enterprises choose the "supply" strategy, and the potential demand-oriented enterprises choose the "not adopt" strategy. In this case, the diffusion of green technology innovation is in a state of failure, because diffusion cannot make up for the losses caused by the adoption of green technologies by potential demand-oriented enterprises. Therefore, a relatively low subsidy rate cannot stimulate the diffusion of green technology innovation in potential demand-oriented enterprises. When $\mu$ gradually increases to 0.9 , the system eventually evolves to a stable state of $(1,1,1)$, indicating that the diffusion of green technology innovation is successful.

In general, the government needs a threshold value to provide subsidies for manufacturing enterprises to invest in green technology innovation, and the diffusion of green technology innovation among manufacturing enterprises can only be realized when this threshold value is exceeded. Ambec and Barla reviewed the empirical evidence available to date in the economic literature, and found that well-designed environmental regulations stimulate innovation which, by increasing either productivity or product value, leads to private benefits [67].

(2) The influence of market-based incentive regulation on the innovation-supplying enterprises

According to the observation of Figure 9, when the value of $\mu$ changes from 0.1 to 0.9 , the group of innovation-supplying enterprises will eventually evolve to the stable state in which all enterprises choose to provide the achievements of green technology innovation. In addition, it has an incentive effect on the speed of innovation-supplying enterprises to provide the achievements of green technology innovation. The higher the subsidy rate, the more obvious the incentive effect. This is because the competitive advantage of green technology of innovation-supplying enterprises steadily decreases with 
the gradual increase of the subsidy. Driven by economic interests, after many games, these enterprises will choose to supply the achievements of green technology innovation to external parties to reduce the marginal cost of the unit product and increase profit [68].

(3) The influence of market-based incentive regulation on the potential demand-oriented enterprises

Government subsidies for green technology innovation influence the adoption behavior of potential demand-oriented enterprises, as shown in Figure 10. When the value of $\mu$ changes from 0.1 to 0.7, the speed at which potential demand enterprise-oriented enterprises evolve to adoption behavior steadily increases, which indicates that the proportion of enterprises adopting the achievements of green technology innovation in the group will also steadily increase. When $\mu=0.9$, the group of potential-oriented demand enterprises will choose the "adopt" strategy. In general, the subsidy rate of green innovation input has an incentive effect on the speed of the evolution of potential demand-oriented enterprises towards the direction of adoption behavior. The higher the subsidy rate, the more obvious the incentive effect.

To be specific, when the subsidy rate is low, given the high cost of green R\&D and unpredictable high risks, potential demand-oriented enterprises are reluctant to take the risk of adopting green technologies. However, when the subsidy rate is sufficiently high, it partially compensates for the cost of green R\&D to enterprises, but also greatly improves the enthusiasm of enterprises for green technology innovation.

\subsection{The Influence of a Combination of Environmental Regulation on the Strategy Selection of the Three Parties}

It can be seen from Figure 8 that when $\mu$ is equal to 0.1 and 0.3 , the diffusion system of green technology innovation will eventually evolve to a stable state in which the government chooses the "regulate" strategy, the innovation-supplying enterprises choose the "supply" strategy, and the potential demand-oriented enterprises choose the "not adopt" strategy. We further observe the influence of the combination strategy of $\lambda$ and $\mu$ on the diffusion of green technology innovation in manufacturing enterprises. It can be seen from Figures 11-13 that when $\mu=0.1$ and 0.3 , the diffusion system of green technology innovation will eventually evolve to $(1,1,1)$ regardless of the value of $\lambda$, and the group of innovation-supplying enterprises will eventually evolve to a stable state in which all enterprises choose to provide the achievements of green technology innovation. However, it is only when $\lambda=0.5$, 0.7, and 0.9 that the potential demand-oriented enterprises finally evolve to a stable state in which all enterprises choose to adopt the achievements of green technology innovation. That is, the government subsidy has a greater impact on the potential demand-oriented enterprises. When the government provides a low subsidy rate to manufacturing enterprises for green technology innovation, potential demand-oriented enterprises will choose the "not adopt" strategy. 


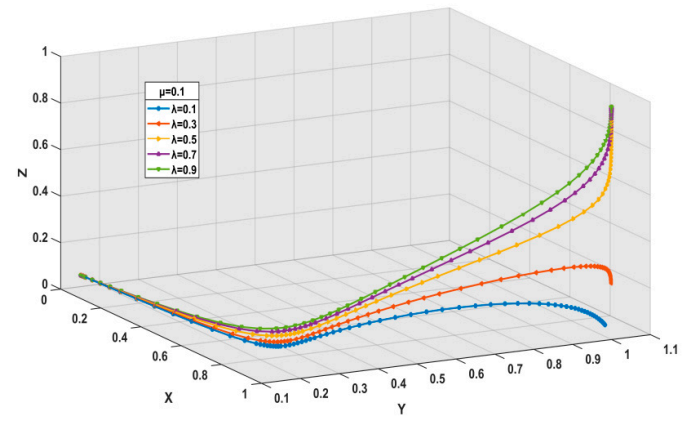

(a) The combination strategy of $\lambda$ and $\mu=0.1$ on the system's evolution trajectory.

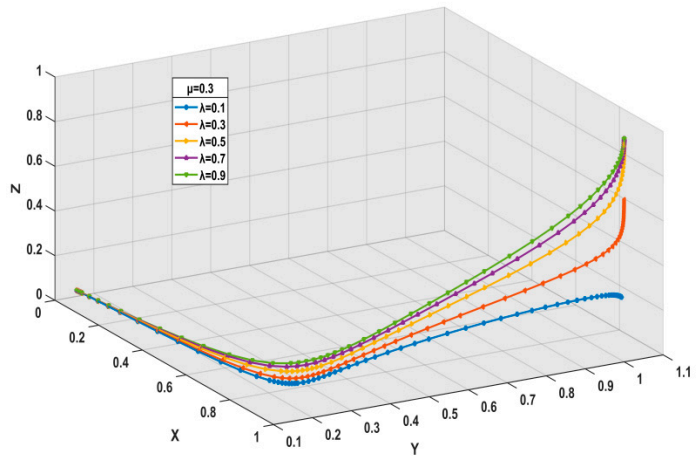

(b) The combination strategy of $\lambda$ and $\mu=0.3$ on the system's evolution trajectory.

Figure 11. The combination strategy of $\lambda$ and $\mu$ on the system's evolution trajectory.

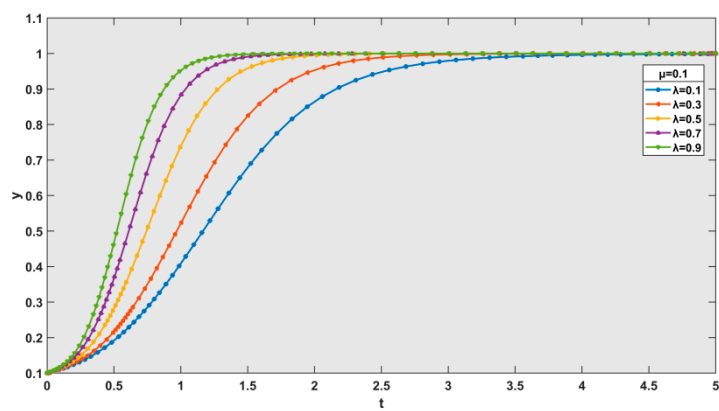

(a) The combination strategy of $\lambda$ and $\mu=0.1$ on the innovation-supplying enterprises' evolution trajectory.

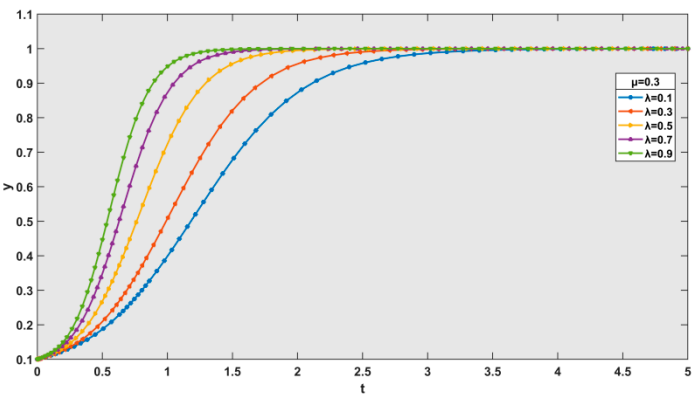

(b) The combination strategy of $\lambda$ and $\mu=0.3$ on the innovation-supplying enterprises evolution trajectory.

Figure 12. The combination strategy of $\lambda$ and $\mu$ on the innovation-supplying enterprises' evolution trajectory. 


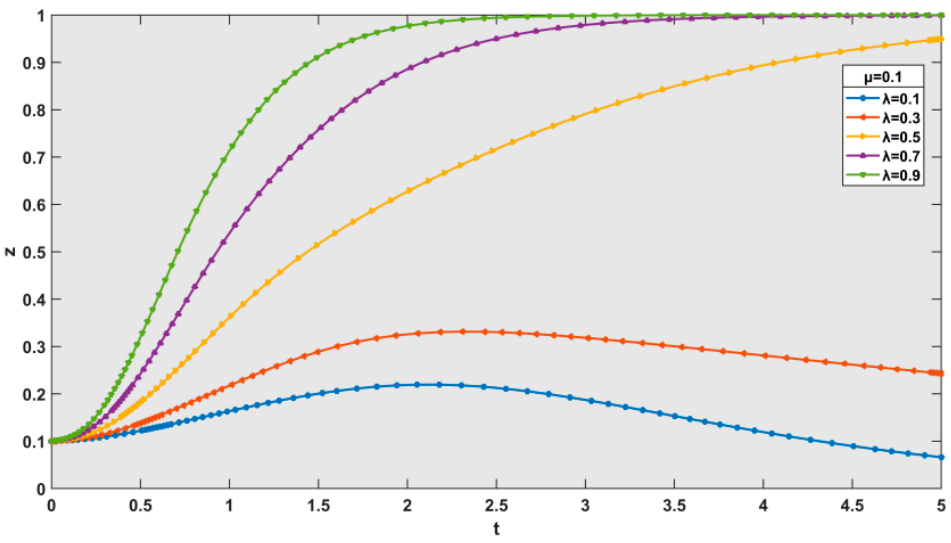

(a) The combination strategy of $\lambda$ and $\mu=0.1$ on the potential demand-oriented enterprises' evolution trajectory.

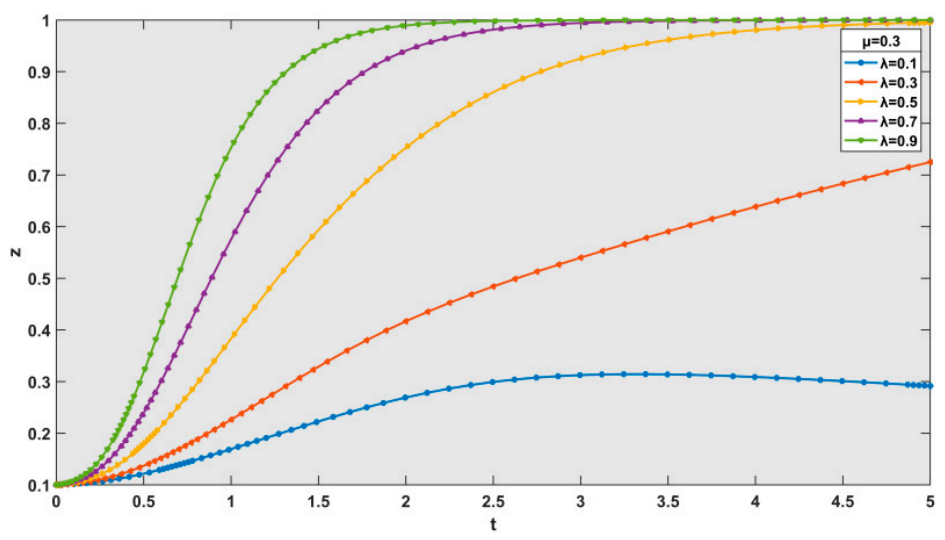

(b) The combination strategy of $\lambda$ and $\mu=0.3$ on the potential demand-oriented enterprises' evolution trajectory.

Figure 13. The combination strategy of $\lambda$ and $\mu$ on the potential demand-oriented enterprises' evolution trajectory.

The implementation of green technology innovation is often accompanied by high R\&D costs and unpredictable risks. When the government subsidy rate is low, potential demand-oriented enterprises cannot gain competitive advantages by adopting the achievements of green technology innovation. Limited by their own limited economic strength, it is difficult for potential demand-oriented enterprises to adopt the achievements of green technology innovation in the short term. Therefore, the government should adopt the two kinds of regulation measures for potential demand-oriented enterprises.

\section{Conclusions and Implications}

\subsection{Conclusions}

The diffusion of green technology innovation has recently become a popular research topic. In practice, the imposition of environmental regulation by the government on manufacturing enterprises is improving. However, it is far from widespread, full, and effective $[69,70]$. Thus, at present, global environmental regulation is becoming increasingly strict. Considering the reality of China, based on the current background of green and sustainable development, and the significant constraints of natural resources and the environment faced by China's manufacturing enterprises, this study closely examined the heterogeneous effects of different types of environmental regulation tools on the diffusion of green technology innovation in manufacturing enterprises. This study helps to promote the green innovation practice of China's manufacturing enterprises and the government's environmental 
regulation reform, and provides a useful reference for guiding the actual decision-making process of enterprises' sustainable development. Furthermore, this study provides a practical theoretical basis for the promotion of a new industrialization path in China. In addition, it has important practical significance and application value for cultivating enterprises' sustainable competitive advantages, and improving China's green innovation policy and environmental regulation system.

To achieve this goal, this paper analyzed the process of diffusion of green technology innovation behavior in manufacturing enterprises under environmental regulation at the micro level. The evolution state of the tripartite game of government, innovation-supplying enterprises, and potential demand-oriented enterprises in the process of diffusion of green technology innovation was also analyzed using simulation. Thus, the development rules and characteristics of the diffusion of green technology innovation were able to be more clearly presented and revealed. This study helps enrich theoretical and methodological research on the innovation diffusion evolution of enterprise green technology. Specifically, this study first analyzed the interaction and participants of diffusion of green technology innovation in manufacturing enterprises, and explores the interests of the government, innovation-supplying enterprises, and potential demand-oriented enterprises. Secondly, based on the evolutionary game theory, a tripartite game model of government, innovation-supplying enterprises, and potential demand-oriented enterprises was constructed. Finally, the evolution process of system, government, innovation-supplying enterprises, and potential demand-oriented enterprises was simulated by numerical simulation.

The following conclusions can be drawn:

(1) When the government does not implement any tools of environmental regulation or the regulatory intensity is relatively small, the diffusion system of green technology innovation eventually evolves to $(1,1,0)$ and the diffusion depth is zero. When the government regulation reaches a certain level, the system of manufacturing enterprises, innovation-supplying enterprises, and potential demand-oriented enterprises eventually chooses to actively promote the diffusion of green technology innovation after a long evolution process. That is to say, innovation-supplying enterprises will actively supply the achievements of green technology innovation, and potential demand-oriented enterprises will actively adopt the achievements of green technology innovation.

(2) The influence of different environmental regulation tools on the strategic selection of manufacturing enterprises is different. Increases of both the punishment intensity and the subsidy rate of green innovation input can increase the probability of manufacturing enterprises carrying out the diffusion of green technology innovation. When the punishment intensity or subsidy rate set by the government is less than a certain threshold value, the incentive effect of promoting the diffusion of green technology innovation among manufacturing enterprises cannot be successfully realized. However, levels of the punishment intensity or subsidy rate higher than a certain threshold value can improve the enthusiasm of manufacturing enterprises to spread the achievements of green technology innovation. Therefore, the greater the punishment or subsidy the government imposes, the more conducive it is to the diffusion of green technology innovation.

(3) The comprehensive use of the two kinds of environmental regulation tools has a heterogeneous influence on the strategic choice of the diffusion subject of green technology innovation in manufacturing enterprises. When the value of $\lambda$ is 0.1 and 0.3 , regardless of the value of $\mu$, the group of innovation-supplying enterprises will ultimately choose to provide the achievements of green technology innovation. However, only when the $\lambda$ is greater than 0.5 can the potential demand-oriented enterprises finally evolve to a stable state in which all of the enterprises choose the "adopt" strategy. Compared with innovation-supplying enterprises, potential demand-oriented enterprises have lower policy sensitivity, and environmental regulation of government acts as a relatively weak constraint on potential demand-oriented enterprises. 


\subsection{Implications}

Green technology innovation as a strategic basis is critical to address the dilemma of green economic development and environmental protection. This paper not only furnishes a different perspective compared to the existing literature to analyze the diffusion of green technology innovation, but also provides ideas for how to adjust the decision-making behaviors related to green technology innovation among manufacturing enterprises under environmental regulation.

The simulation results in this paper are of great significance both in theory and in practice. From the above analysis, the empirical evidence may provide some implications for promoting the diffusion of green innovation. For example, the government should appropriately increase subsidies to manufacturing enterprises. First, the government should provide friendly policies for manufacturing enterprises, such as increasing economic incentives, tax incentives, and institutional guarantees, and strengthen support for green R\&D of manufacturing enterprises, to increase the time available and motivation for enterprises to carry out green innovation activities. Second, in the early stage of the diffusion of green technology innovation, the government should provide a certain proportion of subsidies to innovation-supplying enterprises and potential demand-oriented enterprises that cooperate with the diffusion of green technology innovation. For enterprises of different sizes and economic conditions, government agencies should carry out targeted subsidies according to the types of imported technology, the amount of investment, and other factors. In addition, the government should optimize the policy environment for the diffusion of green technology innovation. First, the government should improve the system for addressing the risks of spreading green technology innovation. In addition to providing fiscal and tax policy support, the government should also establish a risk response mechanism to reduce the uncertain risks of the diffusion of green technology innovation in manufacturing enterprises' introduction, digestion, absorption, and application of new technologies. This would help manufacturing enterprises build confidence and solve existing problems relating to the development of green innovation. Second, the government should formulate appropriate intellectual property policies, such as the institution of green patents and trademarks, and the confidential management of intellectual property. The aim is to fully tap the potential ability of intellectual property and promote the research, application, and promotion of green technologies.

Although this study has achieved its intended objectives, deficiencies remain that are worthy of attention. For example, the diffusion subjects of green technology innovation in manufacturing enterprises not only include innovation-supplying enterprises and potential demand-oriented enterprises, but also intermediary institutions. Furthermore, due to practical reasons, this paper mainly takes into account the economic and institutional factors in the Chinese context when making model assumptions and setting parameters. Thus, international economic and institutional factors are not included in the research scope. However, in practice, the choice of green innovation strategy between innovation-supplying enterprises and potential demand-oriented enterprises depends on the comprehensive influence of domestic and foreign economic and institutional factors. Future research should focus on more stakeholders and influencing factors.

Author Contributions: Conceptualization, M.W.; formal analysis, M.W. and S.L.; investigation, S.Y.; project administration, S.Y.; software, S.L.; visualization, S.L.; writing — original draft, M.W.; writing — review \& editing, S.Y.; materials and analysis tools, H.D. All authors have read and agreed to the published version of the manuscript.

Funding: This research was funded by Baoding Philosophy and Social Science Planning Project grant number [2020047].

Acknowledgments: The authors thank the editors and reviewers.

Conflicts of Interest: The authors declare no conflict of interest. 


\section{References}

1. Hart, S.L.; Dowell, G. A Natural-Resource-Based View of the Firm: Fifteen Years After. J. Manag. 2011, 37, 1464-1479.

2. Ludbrook, F.; Michalikova, K.F.; Musova, Z.; Suler, P. Business Models for Sustainable Innovation in Industry 4.0: Smart Manufacturing Processes, Digitalization of Production Systems, and Data-driven Decision Making. J. Self Gov. Manag. Econ. 2019, 7, 21-26.

3. Gradeck, J.; Octav, N.; Iulia, G.; Gheorghe, G. Big Data Analytics in Industry 4.0: Sustainable Industrial Value Creation, Manufacturing Process Innovation, and Networked Production Structures. J. Self Gov. Manag. Econ. 2019, 7, 34-40.

4. Ooba, M.; Hayashi, K.; Fujii, M. A long-term assessment of ecological-economic sustainability of woody biomass production in Japan. J. Clean. Prod. 2015, 88, 318-325. [CrossRef]

5. Zhao, X.; Zhao, Y.; Zeng, S.; Zhang, S. Corporate behavior and competitiveness: Impact of environmental regulation on Chinese firms. J. Clean. Prod. 2015, 86, 311-322. [CrossRef]

6. Karen, C. Cyber-Physical Smart Manufacturing Systems: Sustainable Industrial Networks, Cognitive Automation, and Big Data-driven Innovation. Econ. Manag. Financ. Mark. 2019, 14, 23-29.

7. Blaut, J.M. Diffusions: A Uniformitarian Critique. Ann. Assoc. Am. Geogr. 1987, 77, 30-47. [CrossRef]

8. Mulder, P.; de Groot, H.L.F.; Hofkes, M.W. Explaining slow diffusion of energy-saving technologies: A vintage model with returns to diversity and learning-by-using. Resour. Energy Econ. 2003, 25, 105-126. [CrossRef]

9. Reinganum, J.F. On the diffusion of new technology: A game theoretic approach. Rev. Econ. Stud. 1981, 48, 395-405. [CrossRef]

10. Yin, S.; Zhang, N.; Li, B.Z. Enhancing the competitiveness of multi-agent cooperation for green manufacturing in China: An empirical study of the measure of green technology innovation capabilities and their influencing factors. Sustain. Prod. and Consump. 2020, 23, 63-76. [CrossRef]

11. Kemp, R.P.M. Environmental policy and technical change: A comparison of the technological impact of policy instruments. Open Access Publ. Maastricht Univ. 2015, 108, 231-233.

12. Medrano, N.; Cornejo-Cañamares, M.; Olarte-Pascual, C. The impact of marketing innovation on companies' environmental orientation. J. Bus. Ind. Mark. 2020, 35, 1-12. [CrossRef]

13. Khan, Z.; Sisi, Z.; Siqun, Y. Environmental regulations an option: Asymmetry effect of environmental regulations on carbon emissions using non-linear ARDL. Energy Source 2019, 41, 137-155. [CrossRef]

14. Wang, Y.; Sun, X.; Guo, X. Environmental regulation and green productivity growth: Empirical evidence on the Porter Hypothesis from OECD industrial sectors. Energy Policy 2019, 132, 611-619. [CrossRef]

15. Delre, S.A.; Jager, W.; Bijmolt, T.H.; Janssen, M.A. Targeting and timing promotional activities: An agent-based model for the takeoff of new products. J. Bus. Res. 2007, 60, 826-835. [CrossRef]

16. D'Orazio, P.; Valente, M. The role of finance in environmental innovation diffusion: An evolutionary modeling approach. J. Econ. Behav. Organ. 2019, 162, 417-439. [CrossRef]

17. Gao, X.; Zhang, W. Foreign investment, innovation capacity and environmental efficiency in China. Math. Comput. Model. 2013, 58, 1040-1046. [CrossRef]

18. Zsifkovits, M.; Günther, M. Simulating resistances in innovation diffusion over multiple generations: An agent-based approach for fuel-cell vehicles. Cent. Eur. J. Oper. Res. 2015, 23, 501-522. [CrossRef]

19. Coad, A.; Haan, P.D.; Woersdorfer, J.S. Consumer support for environmental policies: An application to purchases of green cars. Ecol. Econ. 2009, 68, 2078-2086. [CrossRef]

20. Shi, J.; Tong, X. The Diffusion of 'Green' Technology: Comparison of Three Electronics Industrial Clusters in China. Chin. J. Popul. Resour. Environ. 2010, 20, 120-126.

21. Yang, C.J.; Liu, B.; BI, K.X. Research on the Evolutionary Game of Green Innovation Industry-UniversityResearch Cooperation under the International Technology Spillover. Ecol. Econ. 2019, 33, 86-91.

22. XU, Y.Y.; QI, L.Q. Research on low carbon technological innovation diffusion in enterprises clusters based on evolutionary game theory on complex networks. Chin. J. Popul. Resour. Environ. 2016, 26, 16-24.

23. Xu, J.Z.; Fu, J.W.; Li, F.S. Research on the service innovation diffusion of manufacturing enterprises based on evolutionary game theory. Oper. Res. Manag. Sci. 2018, 27, 177-183.

24. Rennings, K. Redefining innovation-eco-innovation research and the contribution from ecological economics. Ecol. Econ. 2000, 32, 319-332. [CrossRef] 
25. Cai, W.; Li, G. The drivers of eco-innovation and its impact on performance: Evidence from China. J. Clean. Prod. 2018, 176, 110-118. [CrossRef]

26. Shahin, A.; Imanipour, N.; Shahin, A.; Wood, L.C. An integrative approach for structuring and prioritising eco-innovation determinants with a survey in knowledge-based companies. J. Manuf. Technol. Manag. 2020, 31, 799-824. [CrossRef]

27. Oltra, V.; Jean, M.S. Sectoral systems of environmental innovation: An application to the frenchautomotive industry. Technol. Forecast. Soc. 2009, 76, 567-583. [CrossRef]

28. Horbach, J.; Rammer, C.; Rennings, K. Determinants of Eco-innovations by Type of Environmental Impact: The Role of Regulatory Push/Pull, Technology Push and Market Pull. Zew Discuss. Pap. 2011, 78, 112-122. [CrossRef]

29. Yin, S.; Zhang, N.; Li, B.Z. Improving the Effectiveness of Multi-Agent Cooperation for Green Manufacturing in China: A Theoretical Framework to Measure the Performance of Green Technology Innovation. Int. J. Public Health 2020, 17, 3211. [CrossRef] [PubMed]

30. Fussler, C. Driving Eco-Innovation: A Breakthrough Discipline for Innovation and Sustainability; Pitman: London, UK, 1996.

31. Driessen, P.H.; Hillebrand, B. Adoption and Diffusion of Green Innovations; Ios Press Inc.: Amsterdam, The Netherlands, 2003; pp. 343-356.

32. OECD. Sustainable Manufacturing and Eco-Innovation: Towards a Green Economy; Policy Brief-OECD Observer: Paris, France, 2009.

33. Xie, X.; Huo, J.; Zou, H. Green process innovation, green product innovation, and corporate financial performance: A content analysis method. J. Bus. Res. 2019, 101, 697-706. [CrossRef]

34. Stoneman, P. The Economic Analysis of Technological Change; Oxford University Press: Oxford, UK, 1983.

35. Rogers, E.M. Diffusion of Innovation; Free Press: New York, NY, USA, 2003.

36. Wang, Q.; Luo, J.; Zhong, Z.; Borgna, A. $\mathrm{CO}_{2}$ capture by solid adsorbents and their applications: Current status and new trends. Energy Environ. Sci. 2011, 4, 42-55. [CrossRef]

37. Kama, A.A.L.; Fodha, M.; Lafforgue, G. Optimal Carbon Capture and Storage Policies. Environ. Model. Assess. 2013, 18, 417-426. [CrossRef]

38. Boot-Handford, M.E.; Abanades, J.C.; Anthony, E.J.; Blunt, M.J.; Brandani, S.; Mac Dowell, N.; Fernández, J.R.; Ferrari, M.C.; Gross, R.; Hallett, J.P.; et al. Carbon capture and storage update. Energy Environ. Sci. 2014, 7, 130-189. [CrossRef]

39. Haas, J.; Nowak, W.; Palma-Behnke, R. Multi-objective planning of energy storage technologies for a fully renewable system: Implications for the main stakeholders in Chile. Energy Policy 2019, 126, 494-506. [CrossRef]

40. Derakhshan-Nejad, Z.; Lee, W.; Han, S.; Choi j Yun, S.; Lee, G. Effects of soil moisture content on CO2 triggered soil physicochemical properties in a near-surface environment. J. Soil. Sediment. 2020, 20, 2107-2120. [CrossRef]

41. Fraas, A.G.; Lutter, R.W.; Wietelman, D.C. The energy paradox in seemingly competitive industries: The use of energy-efficient equipment on heavy-duty tractor trailers. Energy Policy 2019, 129, 467-480. [CrossRef]

42. Lavery, M.P.; Abadi, M.M.; Bauer, R.; Brambilla, G.; Cheng, L.; Cox, M.A.; Dudley, A.; Ellis, A.D.; Fontaine, N.K.; Kelly, A.E.; et al. Tackling Africa's digital divide. Nat. Photonics 2018, 12, $249-252$. [CrossRef]

43. Saudi, M.H.M.; Sinaga, O.; Roespinoedji, D.S. The Impact of Technological Innovation on Energy Intensity: Evidence from Indonesia. Int. J. Energy Econ. Policy 2019, 9, 11-17. [CrossRef]

44. Strandholm, J.C.; Espínola-Arredondo, A. Investment in Green Technology and Entry Deterrence. BE J. Econ. Anal. Policy 2020, 20, 835-878. [CrossRef]

45. Yang, G.; Guo, Q. Research on the Influencing Factors of Green Technology Innovation Diffusion Based on Multi-Agent Model. J. Ind. Technol. Econ. 2017, 8, 43-50.

46. Li, T.; Liang, L.; Han, D. Research on the Efficiency of Green Technology Innovation in China's Provincial High-End Manufacturing Industry Based on the RAGA-PP-SFA Model. Math. Probl. Eng. 2018, 2018, 1-13. [CrossRef]

47. Hwang, B.G.; Tan, J.S. Green building project management: Obstacles and solutions for sustainable development. Sustain. Dev. 2012, 20,335-349. [CrossRef] 
48. Fawzi, H.; Joakim, T.; Maya, H.; Qi, L. The diffusion of green innovation technology in the construction industry: European passive house knowledge transfer to China. Progr. Ind. Eco. 2017, 11, 164-181.

49. Zhang, X.; Shen, L.; Wu, Y. Green strategy for gaining competitive advantage in housing development: A China study. J. Clean. Prod. 2011, 19, 157-167. [CrossRef]

50. Mohammed Shareef, M.S.H.; Zhang, R.J. Critical Barriers and Challenges in Implementation of Green Construction in China. Int. J. Curr. Eng. Technol. 2016, 6, 435-445.

51. Shi, Q.; Zuo, J.; Huang, R.; Pullen, S. Identifying the critical factors for green construction-An empirical study in China. Habitat Int. 2013, 40, 1-8. [CrossRef]

52. Tran, M. Technology-behavioural modelling of energy innovation diffusion in the UK. Appl. Energy 2012, 95, 1-11. [CrossRef]

53. Arnold, D.G.; Williams, L.H.D. The Paradox at the Base of the Pyramid: Environmental Sustainability and Market-Based Poverty Alleviation. Soc. Sci. Electron. Publ. 2013, 60, 44-59. [CrossRef]

54. Sung, B. Do government subsidies promote firm-level innovation? Evidence from the Korean renewable energy technology industry. Energy Policy 2019, 132, 1333-1344. [CrossRef]

55. Crespi, F.; Ghisetti, C.; Quatraro, F. Environmental and Innovation Policies for the Evolution of green technologies: A survey and a test. Eurasian Bus. Rev. 2015, 5, 343-370. [CrossRef]

56. Xu, J.Z.; Xu, Y.Y. Low-carbon technology innovation di usion under environmental regulation: Evolutionary game analysis based on prospect theory. Syst. Eng. 2015, 33, 118-125.

57. Cao, X.; Xing, Z.Y.; Zhang, L.P. An Evolutionary Game Analysis of New Energy Vehicle Industry Development under Government Regulations. Manag. Rev. 2018, 30, 84-98.

58. Luigi, D.C.; Andrea, D.L. A stackelberg game of innovation diffusion: Pricing, advertising and subsidy strategies. Int. Game Theory Rev. 2001, 3, 325-339.

59. Cantono, S.; Silverberg, G. A percolation model of eco-innovation diffusion: The relationship between diffusion, learning economies and subsidies. Technol. Forecast. Soc. Chang. 2008, 76, 487-496. [CrossRef]

60. Krass, D.; Nedorezov, T.; Ovchinnikov, A. Environmental Taxes and the Choice of Green Technology. Prod. Oper. Manag. 2013, 22, 1035-1055. [CrossRef]

61. Gil-Moltó, M.J.; Varvarigos, D. Emission taxes and the adoption of cleaner technologies: The case of environmentally conscious consumers. Resour. Energy Econ. 2013, 35, 486-504. [CrossRef]

62. Cohen, M.C.; Lobel, R.; Perakis, G. The Impact of Demand Uncertainty on Consumer Subsidies for Green Technology Adoption. Soc. Sci. Electron. Publ. 2015, 62, 868-878.

63. Bendle, N.; Vandenbosch, M. Competitor orientation and the evolution of business markets. Market. Sci. 2014, 21, 781-795. [CrossRef]

64. Wu, J.; Wang, D.; Li, J.; Yang, F.M. Game analysis of hazardous chemicals transport route selection based on reinforcement learning-model. Syst. Eng. Theor. Pr. 2015, 35, 388-393.

65. Yuan, B.; Xiang, Q. Environmental regulation, industrial innovation and green development of Chinese manufacturing: Based on an extended CDM model. J. Clean. Prod. 2018, 176, 895-908. [CrossRef]

66. Wang, F.Z.; Jiang, T. The impact of environmental regulation on the green technology innovation of resource-based industries: Based on the perspective of industry heterogeneity. Res. Financ. Econ. 2015, 8, 17-23.

67. Ambec, S.; Barla, P. Can environmental regulations be good for business? An assessment of the Porter Hypothesis. Energy Stud. Rev. 2006, 14, 601-610. [CrossRef]

68. Qiao, J.J.; Mu, Y.M.; Zhao, X.Q.; Zheng, J.X.; Qi, X.H. The intervention effect of government subsidy on the adoption of low carbon agricultural technology in Shanxi and Hebei provinces. J. Arid Land Resour. Environ. 2016, 30, 46-50.

69. Hafstead, M.A.C.; Williams, R.C.I. Unemployment and Environmental Regulation in General Equilibrium. J. Public Econ. 2018, 160, 50-65. [CrossRef]

70. Yin, S.; Zhang, N.; Dong, H.M. Preventing COVID-19 from the perspective of industrial information integration: Evaluation and continuous improvement of information networks for sustainable epidemic prevention. J. Ind. Inf. Integr. 2020, 19, 100157. [CrossRef] [PubMed]

(C) 2020 by the authors. Licensee MDPI, Basel, Switzerland. This article is an open access article distributed under the terms and conditions of the Creative Commons Attribution (CC BY) license (http://creativecommons.org/licenses/by/4.0/). 